\begin{tabular}{|c|c|}
\hline $\begin{array}{l}\text { ÇÜTAD } \\
\text { Çukurova Üniversitesi } \\
\text { Türkoloji Araștırmaları Dergisi }\end{array}$ & $\begin{array}{c}\text { Cilt 5, Sayı } 1 \\
\text { Haziran } 2020\end{array}$ \\
\hline $\begin{array}{l}\text { ISSN: } 2587-1900 \\
\text { E-ISSN: 2548-0979 }\end{array}$ & $\begin{array}{l}\text { Geliş Tarihi: } 10.03 .2020 \\
\text { Kabul Tarihi: } 18.04 .2020\end{array}$ \\
\hline \multicolumn{2}{|c|}{$\begin{array}{l}\text { Makale Künyesi (Araştırma): Onur, S. (2020). Doğu Türkçesi - Latince } \\
\text { sözlük: vocabularium linguae giagataicae sive 1gureae (lexico ćiagataico) } \\
\text { Çukurova Üniversitesi Türkoloji Araştırmaları Dergisi. } 5 \text { (1), 136-157. }\end{array}$} \\
\hline
\end{tabular}

\title{
DOĞU TÜRKÇESİ - LATINNCE SÖZLÜK: VOCABULARIUM LINGUAE GIAGATAICAE SIVE IGUREAE (LEXICO ĆIAGATAICO)
}

\section{ÖZET}

Samet ONUR ${ }^{1}$

Bu çalışmada, Batılılar tarafından hazırlanan ilk Doğu Türkçesi (Çağatay) sözlüğü olan Vocabularium Linguae Giagataicae sive Igureae (Lexico Ciagataico) adlı eser tanıtılmaktadır. Çalışmada; Avrupa'da hazırlanan Doğu Türkçesi sözlükleri, Vocabularium Linguae Giagataicae sive Igureae'nin içerisinde yer aldığı yazma, Türkçenin Latin harfleriyle yazıldığı ilk eserler, Vocabularium Linguae Giagataicae sive Igureae'nin transkripsiyon sistemi, içeriği ve kaynakları üzerinde durulmuştur. 468 madde başı içeren sözlükte Doğu Türkçesi madde başları, önce Arap sonra da Latin harfleri ile yazılmıştır. Madde başlarının karşısına yine önce Arap sonra da Latin harfleriyle Farsça ve Osmanlı Türkçesi karşılıkları yazıldıktan sonra Latince açıklama verilmiştir. Latince açıklamadan sonra da madde başı sözcügün alındığı kaynak belirtilmiştir. Bazı madde başlarının ardından madde başı sözcüğün alındığı cümle veya beyit, önce Arap sonra Latin harfleriyle yazılmış ardından da Latinceye tercüme edilmiştir.

Anahtar kelimeler: Latince, Doğu Türkçesi, sözlük, sözlükçülük.

\section{EASTERN TURKISH - LATIN DICTIONARY: VOCABULARIUM LINGUAE GIAGATAICAE SIVE IGUREAE (LEXICO ĆIAGATAICO)}

\begin{abstract}
In this study, Vocabularium Linguae Giagataicae sive Igureae (Lexico Ciagataico), the first Eastern Turkish (Chagatay) dictionary prepared by Europeans, is introduced. In the study, information is given about the Eastern Turkish dictionaries prepared in Europe, the manuscript containing Vocabularium Linguae Giagataicae sive Igureae, the first works in which Turkish is written in Latin letters, the transcription system, content and sources of Vocabularium Linguae
\end{abstract}

\footnotetext{
${ }^{1}$ Yeditepe Üniversitesi, Eğitim Fakültesi, Türk Dili ve Edebiyatı Öğretmenliği, Arș. Gör. samet.onur.yoruk@hotmail.com https://orcid.org/0000-0001-8675-9840
} 
ÇÜTAD

Haziran 2020
Doğu Türkçesi - Latince Sözlük: Vocabularium Linguae Giagataicae Sive Igureae (Lexico Ćiagataico)

Giagataicae sive Igureae. In the dictionary containing 468 headwords, Eastern Turkish headwords were written first with Arabic and then Latin letters. Opposite of the headwords, the Persian and Ottoman Turkish equivalents were written first in Arabic then Latin letters, and after that Latin explanations were given. The source from which the headword is taken is shown after the Latin explanation. In some examples, the sentence or couplet from which the headwords were taken was first written in Arabic, then in Latin, and then translated into Latin.

Keywords: Latin, Eastern Turkish, dictionary, lexicography.

\section{GíRiş}

15. yüzyıldan itibaren bilhassa Nevâyi'nin eserlerinin anlaşılması için Türkistan'da, İran'da, Hindistan'da ve Anadolu'da bazıları Doğu Türkçesinden Farsçaya bazıları da Doğu Türkçesinden Batı Türkçesine çok sayıda sözlük hazırlanmıştır. 19. yüzyıldan itibaren Batılıların da Doğu Türkçesiyle ilgilenmeye başladıkları görülmektedir. 1877 yılında Macaristan'a giden Şeyh Süleyman Efendi, Doğu Türkçesi bildiği için burada büyük ilgi görmüş ve Lugat-ı Çagatay ve Türkî-yi Osmân̂̂’nin manzum mukaddimesinde 19. yüzyıl Avrupa'sında Doğu Türkçesine karşı duyulan ilgiyi "Çagatay Türkîsinin rāgıbı köp" şeklinde ifade etmiştir (Durgut, 1995, s. vi). Avrupa'da 19. yüzyıldan itibaren artan bu ilginin neticesinde muhtelif Batı dillerinde çok sayıda Doğu Türkçesi sözlüğü hazırlanmıştır. Çalışmamızda, Batılılar tarafından hazırlanan ilk Doğu (Çağatay) Türkçesi sözlüğü olan ve Zenker'in Türkisch-ArabischPersisches Handwörterbuch adlı sözlüğünde de kaynak olarak kullanılan Vocabularium Linguae Giagataicae sive Igureae (Lexico Ćiagataico) adlı sözlük tanıtılmıştır.

\section{AVRUPA'DA HAZIRLANAN DOĞU TÜRKÇESI SÖZLÜKLERİ}

Avrupa'da Doğu Türkçesi sözlüğü hazırlama girişiminde bulunan ilk müsteşrik Etienne-Marc Quatremère olmuştur (Eckmann, 1988, s. 230). 15 yıl boyunca Doğu Türkçesi üzerine araştırmalar yapan ve dil malzemesi toplayan Quatremère, 3 ciltlik bir Arapça-Farsça-Doğu Türkçesi sözlük yazmayı planlamış ancak bu eseri neşredemeden vefat etmiştir. Quatremère'in vefatından sonra Doğu Türkçesi sözlüğü için hazırlamış olduğu notlarının da içinde bulunduğu kütüphanesi, Bavyera Kralı tarafından saray ve hükümet kütüphanesi hesabına satın alınmıştır (Thury, 1906, s. 227). Quatremère'in malzemesi daha sonra Zenker tarafından kullanılmıştır. Zenker'in ilk fasikülü 1862 yılında yayımlanan Türkisch-Arabisch-Persisches Handwörterbuch adlı 
sözlüğünde hem Doğu Türkçesinin hem de Batı Türkçesinin söz varlığına yer verilmiştir. Zenker'in sözlügünde Doğu Türkçesi maddeler için kaynak olarak Abuşka Lügati, Senglah, Lügat-i Türkî (Kalküta sözlüğ̈), Hulâsa-yı Abbâsî, Mukaddimetü'l Edeb, Ferheng-i Vaŝŝaf, Giganov'un Slovar'rossoysko-Tatarskiy adlı sözlüğü, Muhammed Gali Mahmudov'un Tatar Sözlügüu, Salihcan Kuklaşev'in Tatarca Anotoloji'si ve Quatremère'in yukarıda değindiğimiz notları kullanılmıştır. Zenker'in sözlüğünde Doğu Türkçesi maddeler için bunların dışında kullandığı bir kaynak daha vardır: Vocabularium Linguae Giagataicae sive Igureae. Zenker, sözlüğünün kaynaklarını saydığı bölümde Vocabularium Linguae Giagataicae sive Igureae'den şu şekilde bahsetmektedir: " ... le manuscrit du Vocabularium linguae Iguricae sive Giagataicae de la bibliotheque de l'universite de Leipzig, provenant de la succession de M. de Hammer Purgstall ${ }^{2}$ (Hammer Purgstall'dan Leipzig Üniversitesi Kütüphanesine intikal eden el yazması Vocabularium linguae Iguricae sive Giagataicae) ... " (Zenker, 1862, s. IX). Zenker, Vocabularium Linguae Giagataicae sive Igureae'deki madde başlarını $V L$. kısaltması ile sözlüğüne dahil etmiştir (Zenker, 1862, s. X). Zenker tarafindan Vocabularium Linguae Giagataicae sive Igureae'den faydalanıldığı açıkça belirtilmesine rağmen bu sözlük, araştırmacıların dikkatini çekmemiştir. Doğu Türkçesi sözlükler ve Türkçe-Latince sözlükler üzerine hazırlanan bibliyografik çalışmalarda da Lexico Ćiagataico'dan bahsedilmemektedir (Eren, 1950; Thury 1906; Rahimi, 2014; Rahimi, 2018; İnce ve Akça, 2018; Nalbant, 2017). Vollers kataloğu ve Hammer'in eski kütüphane kayıtları dışında

\footnotetext{
2 Joseph Freiherr von Hammer-Purgstall, Graz'da vilâyet idaresinde görevli önemli bir memurun oğlu olarak dünyaya gelmiştir. 1789'da Viyana'da Orientalische Akademie'ye giren Hammer, burada tercüman olarak yetiştirilmek üzere on y1l tahsil görmüştür. 1799'da İstanbul'a diplomatik görevle tercüman olarak gönderilmiştir. 1802'de Baron Stürmer'in maiyetinde sefâret sekreteri olmuştur. Bu uzun ikamet Hammer'e Osmanlı Devleti'ni ve Mısır'ı tanıma, yaşayan dille temas ve birçok eser toplama imkânı vermiştir. İstanbul'daki ikameti, 7 Mayıs 1806'da Boğdan'daki Yaş şehrine Avusturya konsolosu olarak tayiniyle son bulmuştur. Bir yıl içinde diplomatik mesleği sona ermiş ve bundan sonra tercümanlık göreviyle kaldığı Viyana'da nâdiren resmî gezilerle Avrupa merkezlerine çıkmıştır. Bu uzun Viyana ikameti onun için verimli çalışmalarla geçen bir dönem olmuştur. Ülkesinde saray müşavirliği yapmış, imparatorluk akademisine başkan seçilmiştir. 1835 'te politikayı bırakıp kendini tamamen tarih çalışmalarına vermiştir. Araştırmaları ile sadece Osmanlı Devleti'nin ve Doğu'nun tarihçiliğinde yeni bir dönem başlatmakla kalmayan; İran, Türk ve Arap edebiyatlarından yaptığı çevirilerle Goethe başta olmak üzere Alman edebiyatını da etkileyen ve yeni bir ilham kaynağının doğmasını sağlayan Hammer 23 Kasım 1856'da Viyana'da vefat etmiştir (Ortaylı, 1997, s. 491-494).
} 
ÇÜTAD

Haziran 2020
Doğu Türkçesi - Latince Sözlük: Vocabularium Linguae Giagataicae Sive Igureae (Lexico Ćiagataico)

Lexico Ćiagataico'nun bulunduğu yazmadan bahseden ulaşabildiğimiz tek kayıt Agah Sırrı Levend'e aittir. O da sözlükten değil Vollers kataloğundan hareketle yazmanın sonundaki Latince Behrâm-ı Gûr tercümesinden bahsetmektedir (Levend, 1965, s. 293).

Zenker'in sözlüğünden sonra Avrupa'da hazırlanan Doğu Türkçesi sözlükleri arasında Ármin Vámbéry'nin Čagataische Sprach-Studien adlı eserinin sözlük bölümü (Vámbéry, 1867), Pavet de Courteille'in Dictionnaire Turc-Oriental'i (Courteille, 1870), János Eckmann'ın hazırladığı Chagatay Manual adlı eserin sözlük bölümü (Eckmann, 1988), Jarring'in An Eastern Turki-English Dialect Dictionary adlı sözlüğü (Jarring, 1964) ve Bodrogligeti’nin A Gramer of Chagatay adlı eserinin sözlük bölümü (Bodrogligeti, 2001) sayılabilir. Bunların dışında çeşitli tarihî Doğu Türkçesi sözlüklerinin neşirleri de yapılmıştır. Bu bilgiler ıșığında Vocabularium Linguae Giagataicae sive Igureae veya kısa adıyla Lexico Ćiagataico'nun mühim bir vasfı ortaya çıkmaktadır. Yukarıda izah ettiğimiz üzere Zenker, bu sözlüğü ilk fasikülü 1862 yılında yayımlanan TürkischArabisch-Persisches Handwörterbuch adlı sözlügünde kaynak olarak kullanmıştır. Bu durumda Lexico Ćiagataico'nun yazıldığı tarih, 1862'den sonrası olamaz. Yazmanın Hammer-Purgstall'ın eski kütüphanesinde bulunmuş olması, bu tarihi en az 6 yıl daha geriye yani Hammer'in ölüm tarihi olan 1856 yılına götürür. Lexico Ćiagataico'nun kaynakları arasındaki en yakın tarihli kaynak da Meninski'nin ilk kez 1680 yılında basılan sözlüğü olduğuna göre Lexico Ćiagataico, 1680 - 1856 yılları arasındaki bir tarihte yazılmıştır. Lexico Ćiagataico'nun Hammer'in eski kütüphanesinde bulunmuş olması ve Arap harfli sözcüklerin tamamen Meninski'nin transkripsiyon sistemine göre Latin harflerine aktarılmış olması, bu sözlüğün Hammer'in de 1789 - 1799 yılları arasında tahsil gördüğü Viyana Doğu Dilleri Akademisi'nde (K.K. Akademie für Orientalische Sprachen) hazırlanmış olma ihtimalini güçlü bir ihtimal olarak karşımıza çıkarmaktadır. Viyana Doğu Dilleri Akademisi’ndeki öğretmenlerin 18. yüzyılın sonuna doğru, Meninski'ye dayanan bir transkripsiyon sistemini uygulamaya koydukları bilinmektedir (Römer, 2015). Viyana Doğu Dilleri Akademisi’ndeki öğrenciler tarafından 18. yüzyılın sonlarında hazırlanan bazı el yazmalarıyla Lexico Ćiagataico arasındaki kaligrafik benzerlik de dikkat çekicidir: 
ÇÜTAD

Haziran 2020

Doğu Türkçesi - Latince Sözlük: Vocabularium Linguae Giagataicae Sive Igureae (Lexico Ćiagataico)

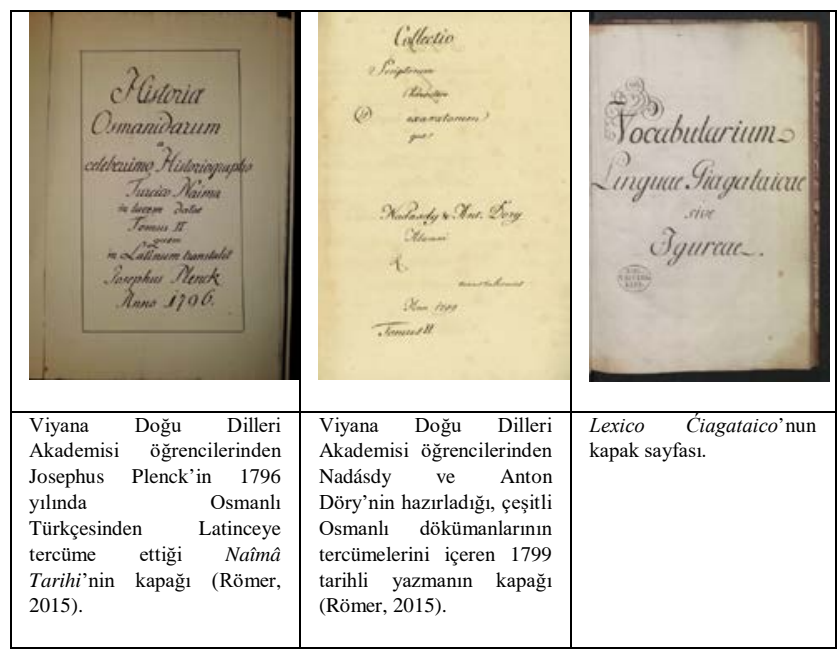

\section{YAZMANIN TAVSIFİ}

Kapak sayfasında Vocabularium Linguae Giagataicae sive Igureae olarak adlandırılan yazma, Leipzig Üniversitesi Kütüphanesinin İslamî Yazmalar Koleksiyonu'nda Vollers 1406 arşiv numarası ile kayıtlı bulunmaktadır. Eserin hiçbir yerinde müellifine veya telif tarihine dair bir bilgi yoktur. Joseph von HammerPurgstall'ın kütüphanesinde 856 arşiv numarası ile kayıtlı bulunan yazma, buradan Leipzig Üniversitesi Kütüphanesine intikal etmiştir (Hammer-Purgstall, 2018, s. 1448). Leipzig Üniversitesi Kütüphanesindeki eski arşiv numarası SS 38'dir. Karl Vollers, yazmanın iç kapağında Joseph von Hammer-Purgstall'ın eski kütüphanesinde bulunduğuna dair bir ibare olduğunu belirtmektedir (Vollers, 1906, s. 365). Leipzig Üniversitesi Kütüphanesi tarafından dijital ortama aktarılmayan iç kapak fotoğrafı, kendileriyle yaptığımız yazışma neticesinde tarafımıza iletilmiştir. Yazmanın kapak sayfasında "Ex bibliotheca, Josephi L. B. de Hammer-Purgstall (no. 876)" ibaresi bulunmaktadır. 326 x $211-225$ x $93 \mathrm{~mm}$ boyutlarındaki yazma, toplam 146 sayfadan (73 varak) oluşmaktadır. İlk iki varak Roma rakamları ile I ve II olarak numaralandırılmıştır. I numaralı varağın her iki yüzü de boştur. II numaralı varağın A yüzüne sözlüğün adı yazılmıştır. Yazmanın boş bırakılan son varağına da Roma rakamı ile III yazılmıştır. Bunların arasındaki varakların her sayfasının üst 
ÇÜTAD

Haziran 2020
Doğu Türkçesi - Latince Sözlük: Vocabularium Linguae Giagataicae Sive Igureae (Lexico Ćiagataico)

kısmına 1'den 140'a kadar sayfa numaraları verilmiştir. Sözlük, 1. ve 121. sayfalar arasında yer almaktadır. Sözlügün bulunduğu sayfalardaki yazılar, dikey konumdaki dikdörtgen cetvellerle çerçevelenmiştir. Dikey konumdaki dikdörtgen cetveller, birinin kısa kenarı diğerinin iki katı olacak şekilde dik bir çizgiyle bölünmüş ve küçük dikdörtgenlerin içine yazı yazılmamıştır. 122. sayfa boştur. 123. ve 137. sayfalar arasında Nevâyi'nin Seb'a-i Seyyâre'sinden Arap harfleriyle yazılmış iki bölüm ve bu bölümlerin Latince tercümeleri yer almaktadır. Bu bölümler cetvelsizdir. 127., 128., 130., 136. ve 138. sayfalar boştur. 139. sayfada Lexico Ćiagataico'da kullanılan kaynakları gösteren bir liste, 140. sayfada ise Leipzig Üniversitesi Kütüphanesinin mührü bulunmaktadır. Arka kapağın iç kısmında esere Leipzig Üniversitesi Kütüphanesinde verilen eski ve yeni arşiv numaraları görülmektedir. Sözlükteki Arap harfli bölümler, nesih hatla harekesiz olarak yazılmıştır. Yazmanın tamamında siyah mürekkep kullanılmıştır. Yarı meşin yarı bez kaplı cilt içinde bulunan yazmanın eksik sayfası yoktur.

\section{TÜRKÇENIN LATIN HARFLERIYYE YAZILDIĞI İLK ESERLER VE LEXICO ĆIAGATAICO'DA KULLANILAN TRANSKRIPSIYON SISTEMI}

Bugünkü bilgilerimize göre, Latin alfabesi Türkçenin yazımı için ilk kez XIV. yüzyıl başlarında kullanılmıştır. Aşağı Volga bölgesinde Kumanlar arasında Hristiyanlığı yaymaya çalışan Fransiskan misyonerleri vaazlarında kullanmak üzere Türkçe öğrenmişler ve birçok dinî metni, Hristiyan dua ve ilâhîlerini Latin harfleri ile Kuman Türkçesine çevirmişlerdi. Latin harfli Türkçe metinleri içeren bu kitabın adı Codex Cumanicus'tur (Tekin, 1997, s. 87). Latin harfleri, Türkçenin yazımı için ikinci olarak Johann Schildtberger tarafından kullanılmıştır. Johann Schildtberger Ankara savaşında Emir Timür'e esir düşmüş ve esaretin sonunda gezi notlarını yayımladığı eserinin arkasına Hristiyan Türklerden derlediği düşünülen Doğu Türkçesi dua metninin transkripsiyonunu eklemiştir. Georgius adlı bir Macar esirinin 1481'de yazdığ 1 Tractatus de moribus, conditionibus et nequitia Turcorum adlı eserde de aralarında Yunus Emre'nin manzumelerinin de bulunduğu Latin harfli Türkçe şiirler bulunmaktadır (Kartalcık, 2009, s. 367). Floransa şehrinin İstanbul balyosluğunda sekreter olarak çalışan Filippo Argenti, Galata'daki yabanc1 tüccarlara kılavuz olmak üzere 1553 yılında Regola del parlere turcho adlı küçük bir konuşma kitabı yazmıştır (Tekin, 1997, s. 90). 1522'de Guillaume Postel; De la République des Turcs adl1 eserini yazmış, 1575'te ise bu esere “Instruction des mots de la langue turquesque les plus communs” başlıklı bölümü eklemiştir. Türkçenin 

Igureae (Lexico Ćiagataico)

öğretimi için hazırlanan bu ekte, Türkçe sözlerin Latin harflerine transkripsiyonu da bulunmaktadır (Kartalcık, 2009, s. 368). Aynı yüzyıl içinde Avrupa'da yayımlanan bir başka Latin harfli Türkçe metin de İstanbul patriği ünlü Gennadios Scholarios'un Fatih Sultan Mehmed'in emri üzerine hazırlamıș olduğu Hristiyan İtikatnamesi'dir. Scholarios'un itikatnamesini 1455 veya 1456 'da hazırladığı bilinmektedir. Bu itikatname Verroria (Karaferye) Kadısı Ahmet Efendi tarafindan Türkçeye çevrilmiş, daha sonra bu Türkçe çeviri Grek harfleri ile yazılmıștır. Grek harfli bu Türkçe metinden haberdar olan Tübingen Akademisi profesörlerinden Martino Crusius da bunu Latin harflerine çevirmiş ve 1584 'te yayımlanan Turco-graeciae libri octo adlı kitabına eklemiştir (Tekin, 1997, s. 91). Bundan sonra İtalyan Cizvit papazlarından Pietro Ferraguto (1580-1650) 1611'de Grammatica turchesa (Türkçe grameri) adlı bir eser yazmıştır (Tekin, 1997, s. 92). 1612 yılında, yine bir papaz olan Hieronymus Megiser, Leipzig'de Institutionum linguae turcicae libri quatuor adındaki Türkçe gramer kitabını yayımlamıştır (Kartalcık, 2009, s. 368). Avrupa'da Türkçenin Latin harfleriyle yazımı bu eserle birlikte az çok standartlaşmıştır. Eserde "i” ile "i”, "u” ile "ü” ayırt edilmemiş, "ö” ünlüsü ise "io" harf dizisi ile gösterilmiştir. Ünsüzlerden "ş" sesi, "sch", "ç" sesi ise "tsch" harf dizileri ile yazılmıştır (Tekin, 1997, s. 93). Megiser'in gramerinden 60 yıl sonra, 1672'de, Almanya'nın Brandenburg (Köln) şehrinde Macar diplomatı Jakab Nagy de Harsâny'nin Colloquia familiaria Turcico-Latina adlı Türkçe-Latince konuşma kitabı yayımlanmıştır (Tekin, 1997, s. 93-94). 1680’de Viyana'da yayımlanan Linguarum Orientalium, Turcica, Arabicce, Persicce, Institutiones adlı Osmanlı Türkçesi grameri, Avrupa'da Türkoloji çalışmalarını başlatan ilk bilimsel eserdir. Leh asıllı Francisci M. Meninski tarafindan yazılan bu eserde Türkçe sözlerin yazımı için daha sistemli ve daha bilimsel bir yöntem izlendiği görülmektedir (Tekin, 1997, s. 94). Ünlüler, "a", “e”, “y” (1), "i”, “o”, "ö”, "u” ve "ü" harfleriyle gösterilir. Ünsüzlerden "ç" ve "ş” aksanlı “ ć " ve " ś " ile, "c" üzeri çizgili " $\mathrm{g}$ ” ile, "hı" sesi "ch", kalın "g" sesi "gh" ile, "y" sesi de "j" ile yazılır. Meninski ince "g" ve "k" seslerini g ve k harflerinin üzerine koyduğu küçük bir "i” harfiyle ( $g^{\mathrm{i}}$, $\left.k^{\mathrm{i}}\right)$, geniz "n"sini de "n" harfinden sonra çekilmiş bir çizgi ile ("n-") göstermiştir (Tekin, 1997, s. 94). Meninski, sözlügünün başındaki "prooemium" adlı bölümde Arap harfli sözcüklerin okunuşu için oluşturduğu bu özel alfabeyi ayrıntılı biçimde açıklamıştır (Meninski, 1680, s. X-XI). Lexico Ćiagataico'da da Meninski'nin oluşturduğu transkripsiyon sistemi kullanılmıştır. Bununla beraber Lexico Ćiagataico'nun yazar veya yazarlarının Doğu Türkçesinin fonetik hususiyetlerine hakim olmadıkları görülmektedir. Sözlükteki Doğu Türkçesi maddeler, yazılışlarına göre Latin harflerine aktarılmışlardır. Doğu Türkçesi 
ÇÜTAD

Haziran 2020
Doğu Türkçesi - Latince Sözlük: Vocabularium Linguae Giagataicae Sive Igureae (Lexico Ćiagataico)

maddelerde imlâda gösterilen ünlüler, uzun ünlü olarak algılanmıştır. Bazen tonlu ve tonsuz ünsüzlerin de hatalı aktarıldığı göze çarpmaktadır:

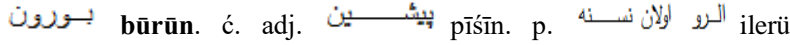
olan nesne. $t$.

Antrerior. Mirỉ Aliśir.

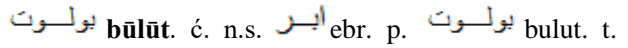

Nubes.

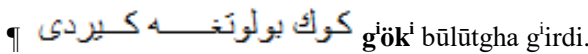

Coelum nubibus obtexit. Mirỉ Aliśir.

\section{LEXICO ĆIAGATAICO’NUN MUHTEVASI}

468 madde başı yer alan sözlükte ilk madde başı olarak ebreş, son madde başı olarak da yılan sözcükleri yer almaktadır. Sözlüğün maddeleri; Arap harflerinin sırasına göre littera I elif, littera $\varphi$ be, littera $ت$ te gibi başlıklar altında toplanmıştır. Doğu Türkçesi madde başları, önce Arap sonra da Latin harfleri ile yazılmıştır. Hemen ardından ćiagataico (Çağatayca) sözcüğünün kısaltması olarak "ć." yazılmıştır. Daha sonra madde başı sözcüğün türü; V. (verbum "fiil”"), n.s. (nomen singularis “teklik isim”), n. propr. (Nomen proprium "özel isim"), part. praet. (participium praeteritum "geçmiş zaman sıfatfiili"), adv. (adverbium “zarf"), adj. (adjectivus "sıfat"), pron. pers. (pronomen personale "kişi zamiri"), num. card. (numerus cardinalis "sayma sayısı"), num. ord. (numerus ordinalis "sira sayısı"), part. (participium "sıfat-fiil”), partic. (particula “edat”), pron. (pronomen "zamir") gibi kısaltmalarla verilmiştir. Doğu Türkçesi madde başlarının türünü gösteren kısaltmalardan sonra sözcüğün Farsça karşılığı önce Arap sonra Latin harfleriyle verilmiş, ardından da "p." (Persicæ "Farsça") kısaltması yazılmıştır. Farsça karşılıkları, aynı şekilde önce Arap sonra Latin harfleriyle yazılmış Osmanlı Türkçesi karşlıklar takip etmektedir. Osmanlı Türkçesi karşılıkların sonuna da "t." (turcicæ "Türkçe”) kısaltması yazılıp hemen ardından Doğu Türkçesi madde başının Latince açıklaması verilmiştir. Latince açıklamadan sonra madde başı sözcüğün alındığı kaynak yazılmıştır. Kaynağın belirtilmediği madde başları da olmakla beraber ekseriyetle kaynak belirtilmiştir: 
ÇÜTAD

Haziran 2020
Doğu Türkçesi - Latince Sözlük: Vocabularium Linguae Giagataicae Sive Igureae (Lexico Ćiagataico)

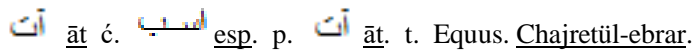

Doğu Türkçesi madde başlarının karşılıklarının Arapça, Farsça ve Osmanlı Türkçesinde ortaklaştı̆̆ 1 durumlarda "a." (arabicæ "Arapça") kısaltmasının da kullanıldığı görülmektedir :

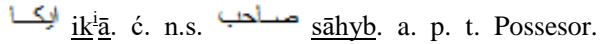

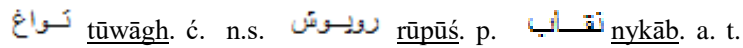
Velum. Ferh.

Bazı madde başlarında, “ q " işaretinden sonra alt maddeler yazıldığı görülmektedir:

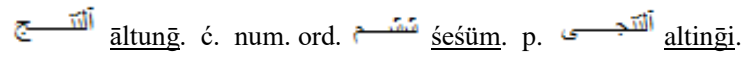
t. Sextus.

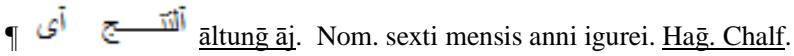

Bazı madde başlarının ardından da yine " q " işaretinden sonra madde başı sözcüğün alındığı cümle veya beyit, önce Arap sonra Latin harfleriyle yazılmış ardından da Latinceye tercüme edilmiştir: adhuc.

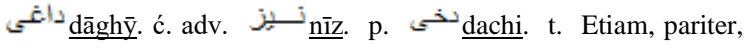

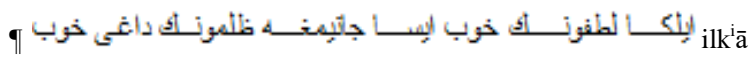

lutfūn- chūb isā, ḡiānīmgha zulmūn- dāghȳ chūb.

Si populo tua beneficentia placet, animæ meæ vel tua quoque crudelitas placet. Mirỉ Aliśir.

Birden fazla anlama sahip olan madde başlarının karşılıkları maddeler halinde verilmiştir. Her anlam için Farsça ve Osmanlı Türkçesi karşılığından önce “i.q." (idem quod "gibi/aynısı") kısaltması yazılmıştır:

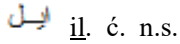

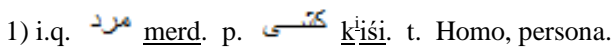


ÇÜTAD

Haziran 2020
Doğu Türkçesi - Latince Sözlük: Vocabularium Linguae Giagataicae Sive Igureae (Lexico Ćiagataico)

2) i.q. خلـ chælk. a. p. t. Populus, plebs.

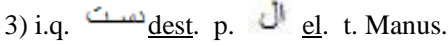

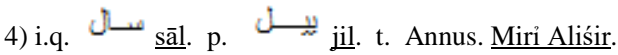

Aynı madde başlarının fonetik varyantları da madde başı olarak verilmiş ve karşısına "i.q. præc." ( idem quod præcedens "öncekiyle aynı") yazılmıştır:

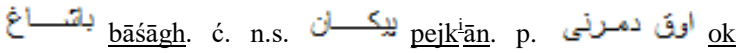
demreni. t. Cuspis teli. Mirỉ Aliśir.

bāśāk. ć. i.q.q. præc.

Madde başı sözcüğün sözlüğün başka bir bölümünde yer alan alt maddelerde veya örneklerde geçtiği durumlarda, tüm açıklamaların sonunda "V." (vide "bakınız") kısaltması ile beraber gönderme yapılan maddedeki Doğu Türkçesi sözcüğün Arap harfli yazımı verilmiștir:

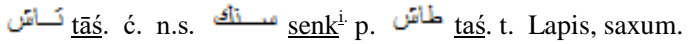

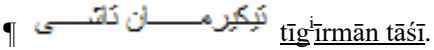

Lapis molaris. Mirỉ Aliśir. V.

Doğu Türkçesi madde başlarına karşılık olarak verilen bazı Osmanlı Türkçesi sözcüklerin Arap ve Latin harfli yazımlarından sonra Meninski'nin sözlüğündeki gibi "vulg." (vulgaris "sıradan") kısaltması ile farklı bir telaffuzları verilmiştir. Halk ağzı olarak da yorumlanabilecek olan bu kısaltma, Peter Zieme'ye göre sözcügün konuşma dilindeki telaffuzunu göstermektedir (Zieme, 1968, s. 72).

vulg. diśari. t.

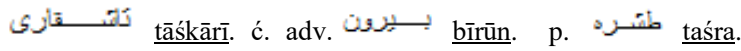

Foris, et foras, extra. Mirỉ Aliśir.

Sözlüğün hazırlayan kişi veya kişilerin muhtemelen ellerindeki el yazmalarındaki yanlış yazımlardan kaynaklanan bazı hatalı okumaları 
ÇÜTAD

Haziran 2020
Doğu Türkçesi - Latince Sözlük: Vocabularium Linguae Giagataicae Sive Igureae (Lexico Ćiagataico)

da göze çarpmaktadır. Örneğin Ferhâd ü Şî̀în'de yer alan “ana tén pādşālık yā gedālık / gedālıḳka tén étmey pādşālıḳ” (Alpay, 2012, s. 138) beytindeki bazı sözcükler, sözlüğe farklı biçimde alınmışlardır.

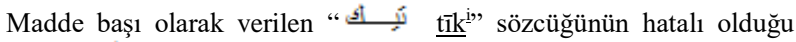
açıktır. “乌ీ tén” olarak yazılması gereken sözcük, muhtelemen “ن” harfinin yazılmadığı veya noktasının konmadığı bir nüshadan ya da nazal n'nin sadece “ "ك " ile gösterildiği Batı Türklük sahasında istinsah edilmiş bir nüshadan alınmıştır:

كَ tî̉

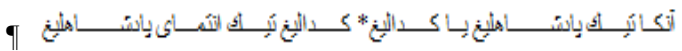

an-a tīk $\mathrm{k}^{\mathrm{i}}$ pādiśāhlȳgh jā k $\mathrm{k}^{\mathrm{i}}$ dālyg: $\mathrm{k}^{\mathrm{i}}$ edālyg tīk intimāỉ pādiśāhlȳgh.

Ipsi et regias et mendici conditio eadem est; idemque illi est pauperis status in comparatione cum regio. Ferhād.

\section{LEXICO ĆIAGATAICO’NUN KAYNAKLARI}

Yazmanın sonunda "Auctores, qui in Lexico ćiagataico citantur." (Lexico ćiagataico'da atıfta bulunulan yazarlar) başlığı altında aşağıdaki liste verilmiştir:

\begin{tabular}{|c|c|}
\hline فر هـاد تافــ & Ferhad. \\
\hline 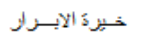 & Chajretül-ebrar. \\
\hline 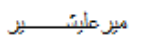 & Mirỉ Aliśir. \\
\hline 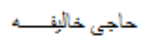 & Haḡ. Chalf. \\
\hline انســــنز نافــ & Isk ${ }^{\mathrm{i}}$ ender name. \\
\hline سبعة سـبلزن & Sebaaỉ sejare. \\
\hline مـبز حبـنز & Mirỉ Haider. \\
\hline Gravius & Grav. \\
\hline
\end{tabular}

Sözlüğün yazar veya yazarları tarafindan Ferhâd ü Şîîn yerine Ferhâd-nâme, Sedd-i İskenderî yerine de İskender-nâme isimleri tercih edilmiştir. Aynı durum Abuşka Lügati'nin müellifinin elinden 
ÇÜTAD

Haziran 2020
Doğu Türkçesi - Latince Sözlük: Vocabularium Linguae Giagataicae Sive Igureae (Lexico Ćiagataico)

çıktığı düşünülen Süleymaniye Kütüphanesi Esad Efendi Koleksiyonu 3264 numarada bulunan nüshada da görülmektedir (Kaçalin, 2011, s. 16). Lexico Ćiagataico'da bazı madde başlarının altında verilen beyitlerin Abuşka Lügati'ndeki örneklerle uyuşmasını da göz önüne aldığımızda, sözlüğü hazırlayan kişi veya kişilerin Abuşka Lügati'nin bir nüshasından faydalandığını söylemek mümkündür:

\section{Lexico Ćiagataico :} adhuc.

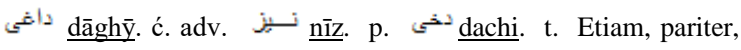

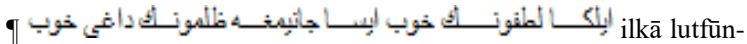
chūb isā, ğiānīmgha zulmūn- dāghȳ chūb.

Si populo tua beneficentia placet, animæ meæ vel tua quoque crudelitas placet. Mirỉ Aliśir.

Abuşka Lügati :

dag̉ı, daḩı demekdür. Bedāyi 'ül Vasaṭ’da bir mațla 'da gelür:

éy cemālin gülşeni hūu u vișālin dagì hūb

élge luṭun hūūb ése cānımg̉a ẓulmun dağı hūb (Kaçalin, 2011, s. $553)$.

\section{Lexico Ćiagataico :}

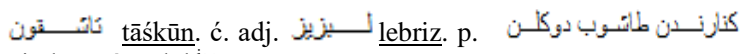
kienārinden taśüp dökililen. t.

Plenus ita, ut fluidum oras vasis superet, et effluat.

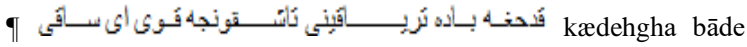
tirijākȳnī tāśkūngia kōj ej sākȳ.

O pocillator, tantum theriacæ vini in poculum influnde, ut oras exuberans effluat. Mirỉ Aliśir.

Abuşka Lügati :

taşḳunca, țaşınca démekdür. Taşḳunca dahı țaşınca démek olur. Nevādirü'ş-Şebāb'da bir ḥüsn-i maḳța da gelür: 
ÇÜTAD

Haziran 2020
Doğu Türkçesi - Latince Sözlük: Vocabularium Linguae Giagataicae Sive Igureae (Lexico Ćiagataico)

ḳadeḥga bāde tiryāḳını taşḳunca uy éy sāḳi 400).

ki ġam zehri bile cānım toluptur belki taşıptur (Kaçalin 2011,

Sözlüğün kaynakları arasında Uluğ Bey'in Zîç-i Cedîd-i Sultânî adlı meşhur zîçi de yer almaktadır (Caferoğlu, 2000, s. 196). Zîç-i Cedîd-i Sultânî dört kitaptan oluşmakta ve trigonometrik, astronomik, coğrafî ve astrolojik tablolar içermektedir. Birinci kitap takvim ve kronolojiye ayrılmış olup burada hicrî, Yezdicerd, Selevki, melikî takvimler ile on iki hayvanlı Türk takvimi hakkında bilgi verilir. Zîç-i Cedîd-i Sultânî'nin kronolojiye ilişkin bu ilk bölümü, Johannes Gravius tarafindan 1650 yılında Londra'da Latince tercümesiyle birlikte neşredilmiştir (Unat, 2013, s. 400-401). Lexico Ćiagataico'da on iki hayvanlı Türk takviminde yer alan hayvanların isimleri, önce temel anlamlarıyla sonra da Türk takviminde karşılık geldikleri sıra ile açıklanmıştır. Hayvan isimlerinin Türk takviminde karşılık geldikleri sıraya dair bilgiler Zîç-i Cedîd-i Sultânî'nin Gravius tarafından yapılan tercümesinden alınmış ve açıklamaların sonuna "grav." kısaltması yazılmıştır :

bol ut. ć.

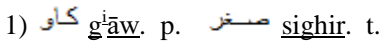

2) n. propr. Nom. secundi anni in eyelo duodeno igureorum. grav.

بـ pārs. ć. pārs. p.t.

1) n.s. Pardus.

2) n. propr. Nom. tertü anni in cyclo duodeno igureorum. grav.

Lexico Ćiagataico'da Mevlânâ Abdullah Hâtifî’nin (ö. 927/1521) bir beyitine de yer verilmiştir. Mevlana Abdurrahmân Câmî'nin kız kardeşinin oğlu olan Abdullah Hâtifî, Timürlüler devrinin sonu ile Safevî döneminin başlarında yaşamıştır. Bir divanı ve hamsesi olduğu bilinen Hâtifî'ye asıl şöhretini kazandıran eseri, hamsesinde yer alan Timur-nâme adlı mesnevisi olmuştur (Yıldırım, 2018, s. 241). Hâtifî’nin Lexico Ćiagataico'da yer alan beyiti, sözlükteki tek Farsça beyittir:

ć. n. propr. 
ÇÜTAD

Haziran 2020
Doğu Türkçesi - Latince Sözlük: Vocabularium Linguae Giagataicae Sive Igureae (Lexico Ćiagataico)

1) Nom. regis Turcarum.

2) Nom. tribus, ex qua Timurus descendisse putatur.

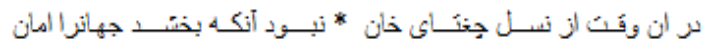

der ān wakt ez neslỉ ćiæghætāi chān : nebūd ānki bæchśed gihānrā āmān.

Illa tempore e stirpe ćiagatajensium non erat Chanus, qui mundo pacem reddidit. Mewlana Hatifi.

Lexico Ćiagataico'ya kaynaklık eden eserlerden bir diğeri ise Meninski'nin Thesaurus Linguarum Orientalium (Thesaurus linguarum orientalium, Turcicae, Arabicae, Persicae, continens nimirum lexicon Turcico-Arabico-Persicum et grammaticam Turcicam) adlı meşhur sözlüğüdür. Lexico Ćiagataico'da Thesaurus

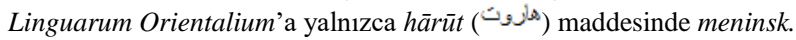
kısaltmasıyla atıfta bulunulmuştur. Bununla beraber Lexico Ćiagataico'da kullanılan kısaltmalar, transkripsiyon sistemi ve vulg. kısaltmasıyla gösterilen Osmanlı Türkçesi sözcüklerin yaygın telaffuzlarının gösterildiği maddeler Thesaurus Linguarum Orientalium'la büyük oranda benzerlik göstermektedir. Bu bağlamda Abuşka Lügati'yle beraber Thesaurus Linguarum Orientalium'un da Lexico Ćiagataico'nun ana kaynaklarından biri olduğunu söylemek mümkündür:

sأزوك hārūt. ć. p. n. propr. Nom. angeli corrupti, socii alterius s mārūt dicti : quos ambos sic describit Hafizii poetæ commentator:

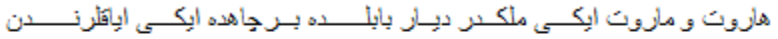

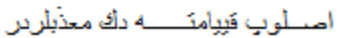

hārūt we mārūt ik ${ }^{\mathrm{i}} \underline{i}$ meleki ${ }^{\mathrm{i}}$ tür, dijārỉ bābelde bir ćiahde ik ${ }^{\mathrm{i}} \underline{i}$ ajaklarindan asylup kyjāmete dek

Harut et Marut duo sunt angeli, quos in terram missos humanam assumsisse formam fabulantur Muhamedani, atque cum mulieribus conversando corruptos fuisse adeo, ut adulteria, et homicidia commiserint, in quoroum poenam in puteo quodam babylonico pedibus appensi, capitibus deorsum perpetuo cruciantur, et ad extremum usque judicii diem cruciandi putantur. Meninsk. 
ÇÜTAD

Haziran 2020
Doğu Türkçesi - Latince Sözlük: Vocabularium Linguae Giagataicae Sive Igureae (Lexico Ćiagataico)

(krş. Thesaurus Linguarum Orientalium, s. 5428)

Lexico Ćiagataico'da, Avrupa'da Hagi Chalfa (Hacı Halîfe) adıyla tanınan Katip Çelebi’ye de atıf yapıldığı görülmektedir. Uygurların sıra sayıları ile oluşturdukları ay adları, Katip Çelebi'den alınmış ve Hağ. Chalf. kısaltması kullanılmıştır. Bu maddelerin ikisinde arkaik özellikler göze çarpmaktadır. Eski Türkçede sıra sayıları yapan $+n c ̧$ ekinin bir ve iki sayılarına eklenmediği bilinmektedir. Köktürkçede birinci anlamında yalnızca ilk(i), Uygurcada ise genellikle başdınķı, nadiren de eyilki sözcükleri; ikinci anlamında ise her iki dönemde de ekinti sözcügü kullanılmıştır. Eski Türkçedeki sayı sisteminin değişmesiyle birlikte ilk defa on birinç, on ekinç, yigirmi birinç, yigirmi ekinç gibi sıra sayıları ortaya çıkmış ve bu da zamanla örnekseme yoluyla birinç birinçi ve ikinç ikinçi şeklinde kurallı sıra sayılarının ortaya çıkmasını tetiklemiştir. İlk defa Divânu Lugâti 't-Türk'te madde başı olarak görülen birinç kelimesi, "Kurala uygun bir kelimedir, az kullanılır" şeklinde açıklanmıştır. Kaşgarlı bu açıklamayı 11. yüzyılda, yani örneksemenin etkisini göstermeye başladığı dönemde yazmıştır. Nihayet ekinti ikinti sözcüğü de aynı dönemde yerini çoktan kurallı olan ikinç sözcüğüne bırakmış ve kendisi de ikindi (vakti) sözcügünde ve bir ikindi söz öbeğinde "birbiri, biri ve öbürü" şeklindeki yeni anlamlarını kazanmıştır (Bacanlı, 2012, s. 78). Lexico Ćiagataico'daki ikind madde başı ve ikinday alt maddesinde ikind sözcügünün Köktürkçe ve Eski Uygur Türkçesinde olduğu gibi ikinci anlamında kullanıldığ görülmektedir. Ne var ki buradaki ikind madde başına şüpheyle yaklaşmak gerektiğini düşünmekteyiz. Lexico Ćiagataico'yu hazırlayan kişi veya kişilerin Katip Çelebi'den alınan ikinday sözcüğünden hareketle ikinci anlamında ikind madde başını kurguladıkları düşünülebilir. Zira Lexico Ćiagataico'da yer alan başka bir madde başı olan atḳunça sözcüğünün Osmanlı Türkçesi karşılığ1 olarak "olunca" sözcüğünün verilmesi de bu görüşümüzü destekler niteliktedir. Lexico Ćiagataico'yu hazırlayan kişi veya kişiler tarafindan, yüksek ihtimalle Abuşka Lügati'ndeki Doğu Türkçesi tay at ķunça ibaresine Batı Türkçesi șubh olınca karşılığı verilmesinden hareketle, at k̦unça ve olınca arasında denklik kurulmuştur. Bu tarz hatalar, Lexico Ćiagataico'nun yazar veya yazarlarının Doğu Türkçesine tam olarak hakim olmadığını da göstermektedir. ikinday sözcügüne dönecek olursak, bu ikindi ve ay sözcüklerinin birleşimi ile ortaya çıkmış bir birleşik sözcüktür. Baskın olan "a" ünlüsünün yanında kalan "i”" ünlüsü kaynaşma neticesinde düşmüş ve ikindi ay > ikinday biçimi ortaya çıkmıştır (Coşkun, 2008, s. 58-59; Ergin, 1984, s. 51-52). 
ÇÜTAD

Haziran 2020
Doğu Türkçesi - Latince Sözlük: Vocabularium Linguae Giagataicae Sive Igureae (Lexico Ćiagataico)

Secundus.

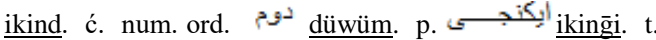

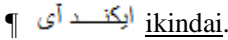

nom. secundi mensis anni igurei. $\underline{\mathrm{Ha} \overline{\mathrm{g}} \text {. Chalf. }}$

Lexico Ćiagataico'da Katip Çelebi'ye atıf yapılan ve arkaik özellik gösteren bir diğer madde başı da bir yegminç olarak karşımıza çıkmaktadır. Eski Türkçenin sayı sistemlerinden biri olan "bir üst onludan alma" sistemine göre önce birler hanesinden bir say1, ardından istenilen onlunun bir üstündeki onlu söylenir: eki yegirmi “12”, bir otuz “21”, altı kırk “36” vb. Köktürk ve Eski Uygur metinlerinde görülen bu sistem, Hakaniye Türkçesi ve sonrasındaki tarihî Türk yazı dillerinde görülmemektedir (Kaymaz, 2002, s. 421). Hakaniye Türkçesinden itibaren günümüz Türk lehçelerinde görülen sayı sistemine geçilmiştir. Tenişev'e göre eski sistemden yeni sisteme geçiş, 8.-11. yüzyıllar arasında yaklaşık 2,5 asırlık bir sürede gerçekleşmiştir (Bacanl1, 2012, s. 78). Köktürk ve Eski Uygur metinlerinde görülen bu sistem günümüzde yalnızca Sarı Uygur ve Saha Türkçelerinde yaşamaktadır (Kaymaz, 2002, s. 423; Gülsevin, 1994, s. 62). Lexico Ćiagataico'da yer alan bir yegminç maddesindeki yegminç sözcügünde ses değişmesi meydana geldiği görülmektedir: yegirminç > yegminç. Eski Türkçe döneminden çok sonra gerçekleşmiş olması gereken bu değişim, söz konusu "bir üst onludan alma" sayı sisteminin, edebî eserlere yansımasa da bazı Türk toplulukları arasında kullanılmaya devam ettiğini göstermektedir. Sarı Uygur Türkçesinde yegirmi > yegmi değişimi gerçekleşmemiştir. Eski Türkçe yegirmi sözcüğü Sarı Uygur Türkçesinde yigirmi yigırma biçimlerinde yaşamaktadır (Gulcalı, 2017, s. 150). Dolayısıyla Lexico Ćiagataico'daki bir yegminç örneği, "bir üst onludan alma" sayı sisteminin, Eski Türkçe döneminden sonra Sarı Uygurlar dışındaki bir Türk topluluğu tarafından da kullanıldığını veya ay adlarında donmuş olarak yaşatıldığını göstermektedir.

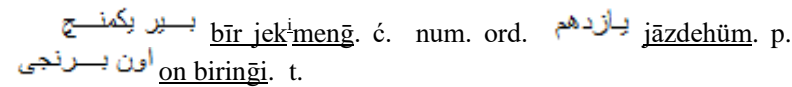

Undecimus.

I igurei. Hāğg. Chalf. 

Igureae (Lexico Ćiagataico)

\section{KAYNAKÇA}

Bacanlı, E. (2012). Geçmişten günümüze Türkçenin sayıları ve sayı sistemi. Bilim ve Teknik Dergisi. 76-78.

Bodrogligeti, A. J. E. (2001). A gramer of Chagatay. Muenchen: Lincom Europa.

Caferoğlu, A. (2000). Türk dili tarihi II. İstanbul: Enderun Yay.

Coşkun, M. V. (2008). Türkçenin ses bilgisi. İstanbul: IQ Yayınları.

Courteille, P. (1870). Dictionnaire Turc-Oriental. Paris: Impr. impériale.

Durgut, H. (1995). Şeyh Süleyman Efendi-i Buhari Lügat-ı Çağatay ve Türki-i Osmani (cild-i evvel) adll eserin transkripsiyonu. Yüksek lisans tezi, Trakya Üniversitesi Sosyal Bilimler Enstitüsü, Edirne.

Eckmann, J. (1979). Tarihî Türk şîveleri (Mehmet Akalın, Çev.). Ankara: Sevinç Matbaası.

Eckmann, J. (1988). Çağatayca el kitabı (Günay Karaağaç, Çev.). İstanbul: İ. Ü. Edebiyat Fakültesi Yayınları.

Eren, H. (1950). "Çağatay lügatleri hakkında notlar. Ankara Üniversitesi DTCF Dergisi. 8 (1-2), 145-163.

Ergin, M. (1984). Türk dil bilgisi. İstanbul: Boğaziçi Yayınları.

Gulcalı, Z . (2017). Sarı Uygurcadaki ses değişmeleri üzerine. Türk Dünyası Dil ve Edebiyat Dergisi, 44, 121-158.

Gülsevin, G. (1994). Göktürk Anttları ile yaşayan üç lehçemizin (Halaç, Çuvaş ve Saha/Yakut) tarihi ilgi düzeni. Türk Dili Araştırmaları Ylllığı - Belleten. 38, 55-64.

Hammer-Purgstall, J. V. (2018). Teil 3/3.2: materialien / höflechner, walter [herausgeberIn]; Wagner, Alexandra [herausgeberIn] ; Koitz-Arko, Gerit [herausgeberIn] et al. - version 2-2018. - Graz : ADEVA, 2018 / (publikationen aus dem Archiv der Universität Graz; band 46) / (quellen zur geschichtlichen Landeskunde der Steiermark; band 30) (08.09.2019). Erişim adresi: http://gams.uni-graz.at/hp/pdf/Band_1.pdf

İnce, Y. ve Akça, B. (2018). Osmanlı döneminde Latin harfleriyle Türkçe yazılan eserler ve yazarları. Erdem Dergisi. 73, 5-42. 
ÇÜTAD

Haziran 2020
Doğu Türkçesi - Latince Sözlük: Vocabularium Linguae Giagataicae Sive Igureae (Lexico Ćiagataico)

Jarring, G. (1964). An Eastern Turki-English dialect dictionary. Lund: CWK Gleerup.

Kaçalin, M. S. (2011). Niyâzî Nevâyî'nin sözleri ve Çă̆atayca tanıklar, El-Lugatu'n-Neva'iyye ve'l-İstişhadatu'l-Çagata'iyye. Ankara: Türk Dil Kurumu Yayınları.

Kartalcık, V. (2009). Geçmişten günümüze Türk dünyasında alfabe gelişimi. In: 1st International Symposium on Sustainable Development, June 9-10, 2009, Sarajevo, Bosnia and Herzegovina.

Kaymaz, Z. (2002). Türklerde sayı sistemleri. Türkler Ansiklopedisi (C. 3, 419-426). Yeni Türkiye Yayınları.

Levend, A. S. (1965). Ali Şir Nevâ̂-hayatı, sanatı ve kişiliği (I. Cilt.), Ankara: Türk Tarih Kurumu Basımevi.

Meninski, F. (1680). Thesaurus linguarum orientalium. TurcicaeArabicae-Persicae lexicon Turcico-Arabico-Persicum (I. Cilt.). Vienna.

Nalbant, B. (2017). Türkistan, İran, Anadolu sahası Doğu Türkçesi sözlük ve gramerleri. Modern Türklük Araştırmaları Dergisi. 14 (4), 120-147.

Ortayl1, İ. (1997). HAMMER-PURGSTALL, Joseph Freiherr von. Türkiye Diyanet Vakfi İslâm Ansiklopedisi (C. 15, 491-494). Türkiye Diyanet Vakfi Yayınları.

Rahimi, F. (2014). Çağatay Türkçesi ve edebiyatı üzerine bir bibliyografya denemesi. Turkish Studies. 9 (3), 1157-1218.

Rahimi, F. (2018). Çağatay Türkçesi sözlükleri bibliyografyası. Uluslararası Türkçe Edebiyat Kültür Eğitim (TEKE) Dergisi. 7, 69-104.

Römer, C. (2016). Early transcription methods at the K.K. Akademie Orientalischer Sprachen in Vienna according to students' exercise books. (15.10.2019). Erişim adresi: https://dighist.hypotheses.org/1171

Tekin, T. (1997). Tarih boyunca Türkçenin yazımı. Ankara: Simurg Yayınları.

Thury, J. (1915). Orta Asya Türkçesi üzerine tetkikler (Ragıp Hulusi, Çev.). Milli Tetebbular Mecmuası. 1 (2), 207-233. 
ÇÜTAD

Haziran 2020
Doğu Türkçesi - Latince Sözlük: Vocabularium Linguae Giagataicae Sive Igureae (Lexico Ćiagataico)

Unat, Y. (2013). Zîc-i Uluğ Bey. Türkiye Diyanet Vakfi İslâm Ansiklopedisi (C. 44, 400-401). Türkiye Diyanet Vakfı Yayınları.

Vámbéry, Á. (1867). Ćagataische Sprachstudien enthaltend grammatikalischen Umriss, Chrestomathie und Wörterbuch der ćagataischen Sprache. Leipzig.

Vocabularium linguae Giagataicae sive Igureae, Leipzig Üniversitesi Kütüphanesi, İslamî Yazmalar Koleksiyonu, Vollers 1406.

Vollers, K. (1906). Katalog der islamischen, christlich-orientalischen, jüdischen und samaritanischen Handschriften der UniversitätsBibliothek zu Leipzig. Leipzig.

Yıldırım, M. (2018). Abdullah Hâtifî’nin hayatı ve bir tarih kaynağı olarak Timurnâme'sinin değeri. Journal of Turkology. 28 (2), 231-254.

Zenker, J. T. (1862). Türkisch-Arabisch-Persisches handwörterbuch (dictionnaire Turc-Arabe-Persan) (I. Cilt.). Leipzig.

Zieme, P. (1968). Meninski sözlüğünün dili üzerine. XI. Türk Dil Kurultayında Okunan Bilimsel Bildiriler 1966 içinde (71-75). Ankara: Türk Dil Kurumu Yayınları. 
ÇÜTAD

Haziran 2020

Doğu Türkçesi - Latince Sözlük: Vocabularium Linguae Giagataicae Sive Igureae (Lexico Ćiagataico)

\section{TIPKIBASIM}

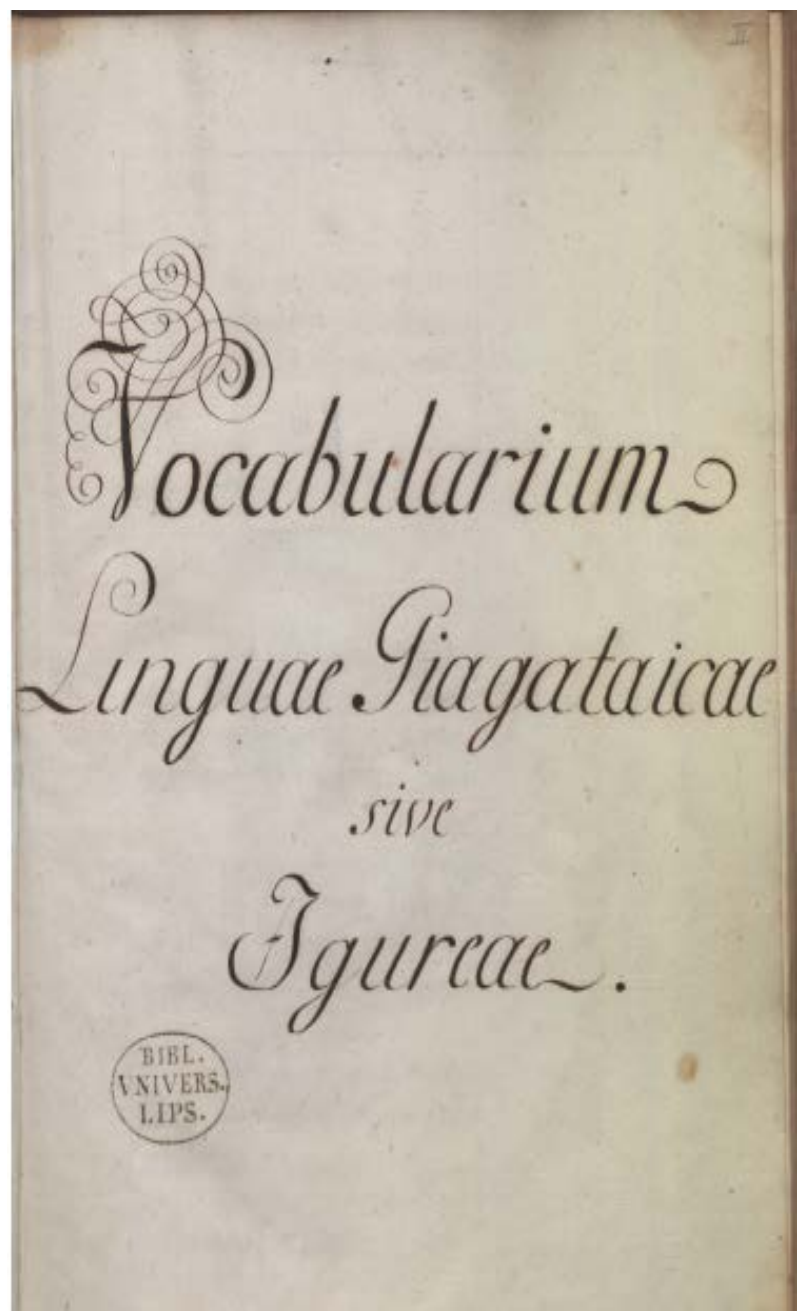


ÇÜTAD

Haziran 2020
Doğu Türkçesi - Latince Sözlük: Vocabularium Linguae Giagataicae Sive Igureae (Lexico Ćiagataico)

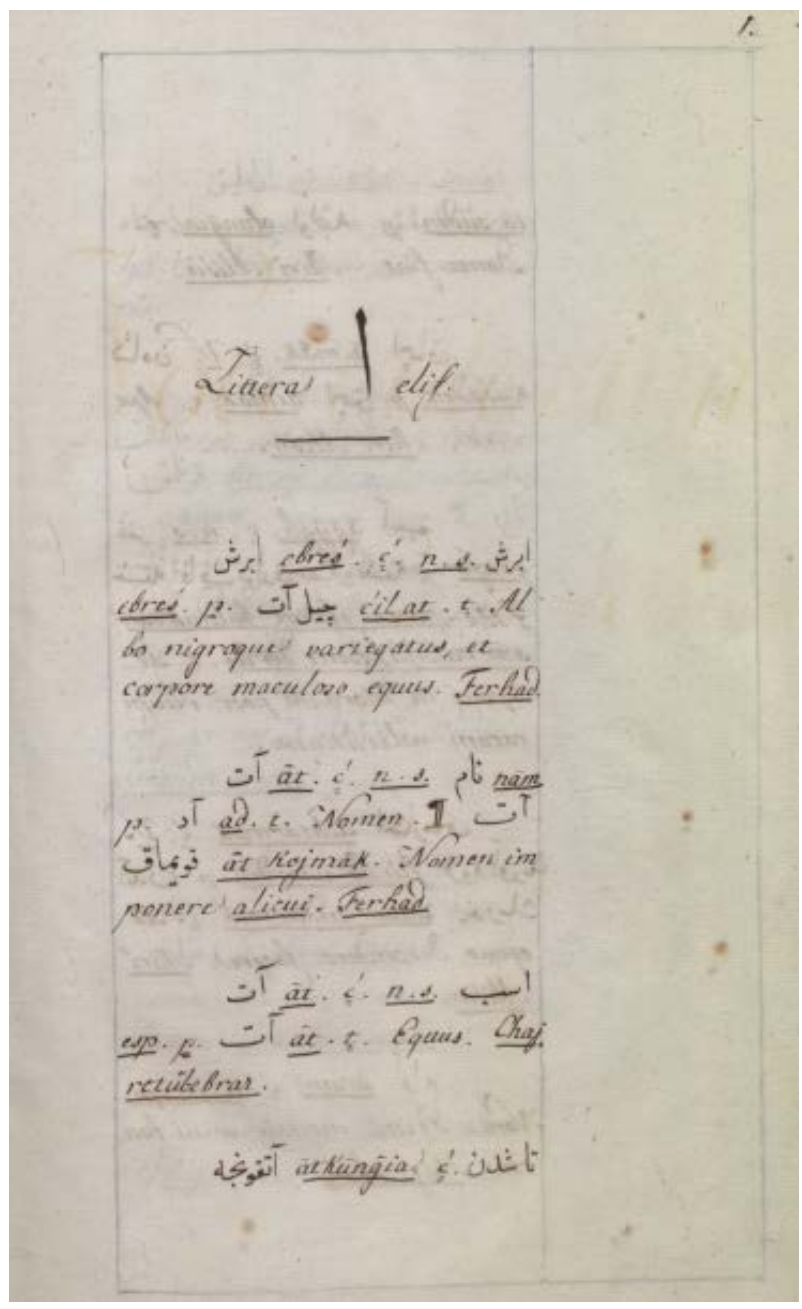


Doğu Türkçesi - Latince Sözlük:

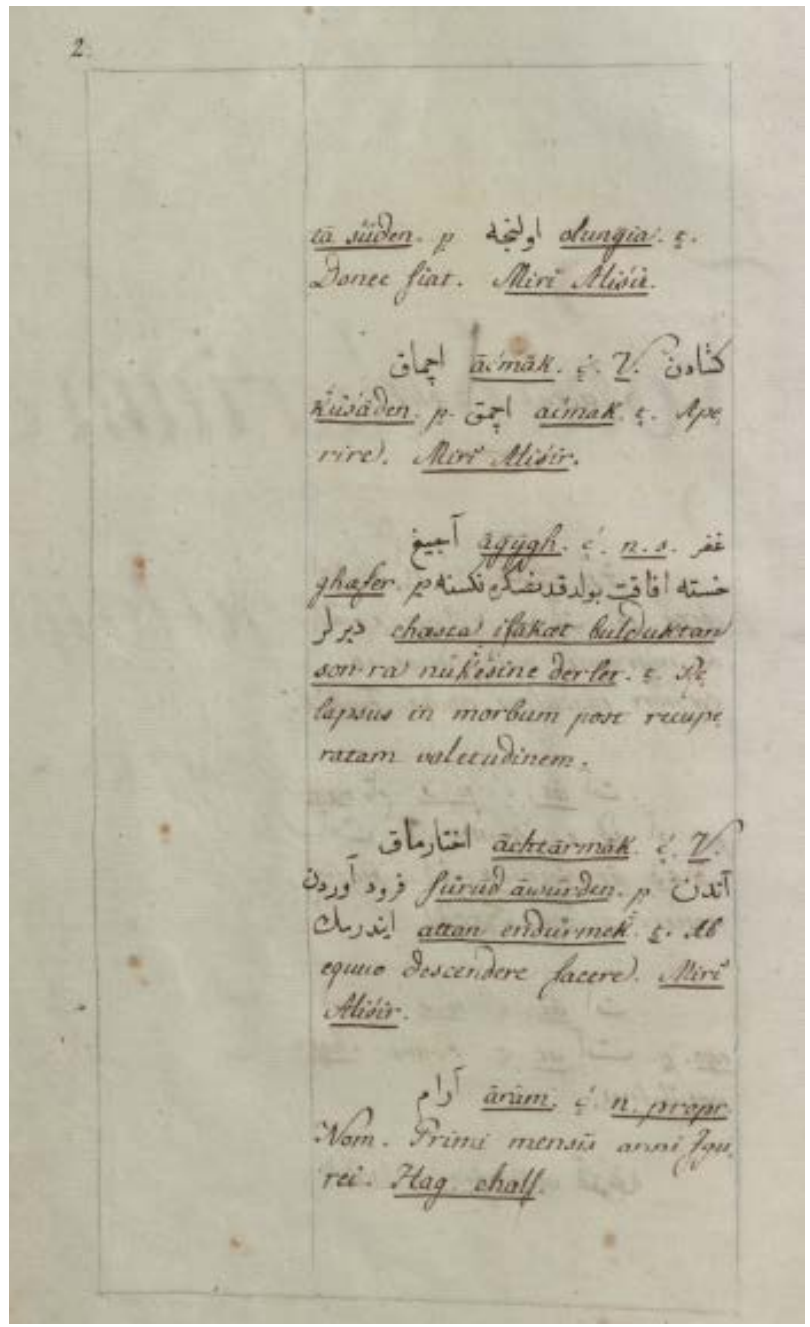

